\title{
COMPARISON OF OUTCOMES WITH THREE ATRIAL INCISIONS FOR MITRAL VALVE OPERATIONS
}

\section{Right lateral, superior septal, and transseptal}

From the Division of Cardiac Surgery, Spartanburg Regional Medical Center, Spartanburg, S.C.

Supported by the Cardiothoracic Research and Education Foundation.

Received for publication June 2, 1994.

Accepted for publication Sept. 30, 1994.

Address for reprints: Joe R. Utley, MD, $100 \mathrm{E}$

Wood St., Suite 300, Spartanburg, SC 29303.

Copyright (C) 1995 by Mosby-Year Book, Inc.

$0022-5223 / 95 \$ 3.00+0 \quad \mathbf{1 2} / \mathbf{1} / \mathbf{6 0 9 7 0}$
We compared the preoperative status, operative factors, and postoperative outcomes among patients having mitral valve operations with three atrial incisions. The incisions were right lateral $(n=66)$, superior septal $(n=46)$, and transseptal $(n=$ 37). Differences in patient and operative factors among the groups were not predictors of adverse postoperative outcomes with multiple regression analysis. Postoperative pulmonary failure was less common in the superior septal group. Patients in the superior septal group more commonly required permanent pacemakers than those in the right lateral group. In patients with sinus rhythm before operation, sinus rhythm had returned before hospital discharge more commonly in those in the right lateral group ( 35 of $44,80 \%$ ) than in those in the superior septal group (18 of 28, 46\%) or in the transseptal group $(9$ of $13,69 \%)$. With multiple regression analysis the type of atrial incision was not a predictor of postoperative pulmonary failure or need for permanent pacemaker. Right lateral and transseptal atrial incisions were predictors of retention of sinus rhythm after operation. We conclude that the results of superior septal incision are comparable with those of other incisions except for a slightly greater risk of loss of sinus rhythm. One must weigh the technical advantages of the superior septal incision against the risk of loss of sinus rhythm. (J THORAC CARDIOVASC SURG 1995;109:582-7)

Joe R. Utley, MD, * Steven A. Leyland, MD, and Tuan Nguyenduy, MD, Spartanburg, S.C.
$R$ ecent reports of the use of the superior septal incision for mitral valve procedures suggest that it is a safe approach and offers certain advantages especially in reoperations and in the presence of a small left atrium. ${ }^{1-7}$ Previous reports suggested that there may be a risk of losing sinus rhythm with the superior septal incision., ${ }^{4,5}$ The right lateral incision has been the traditional approach to the mitral valve. ${ }^{8}$ We have also used the transseptal incision through the fossa ovalis and adjacent septum. ${ }^{9,10}$ Recently we have used the superior septal approach with increasing frequency. We have studied our experience with these three approaches to determine whether the type of atrial incision was a contributing factor in any adverse postoperative outcomes.

\section{Methods}

Data were collected prospectively in 149 patients having mitral valve operations with or without associated operative procedures from October 15, 1983, to May 21, 1992. Patient, operative, and postoperative factors included in the analysis are shown in Tables I, II, and III. The criteria used for determining the presence or absence of the various factors have been described in previous publications. ${ }^{11-15}$ Data were recorded on clinical database software (Patient Analysis and Tracking System, Dendrite Inc., Portland, Ore.). Data were transferred to SPSS/PC software (Statistical Package for the Social Sciences, SPSS, Inc., Chicago, Ill.) for single and multiple regression and $\chi^{2}$ analysis.

Patients were not assigned to the incision groups in a random manner. At the beginning of this experience the right lateral incision was used unless exposure of the tricuspid valve was necessary. When exposure of the tricuspid valve was necessary the transseptal incision was used. We also used the transseptal approach in some patients who required reoperation. We first extended the transseptal incision superiorly into the superior left atrial wall in September 1987 to create the superior septal incision. The superior septal incision had not been described at that time. We then began using the superior septal incision with reoperations or a small left atrium and if exposure of the tricuspid valve was needed. With increasing experience we used the superior septal incision in most patients with a small left atrium or in those who required reoperation. At present the superior septal incision is the incision of choice in patients not in sinus rhythm and in patients in sinus rhythm in whom the technical advantages of the incision are believed to outweigh the risk of loss of sinus rhythm.

Bicaval cannulation was done in all patients. Caval occlusion around the cannula was accomplished with tourniquets of umbilical tape or caval occluding clamps. All procedures were done with the aorta clamped. Cold blood intermittent cardioplegia was used. The volume of cardioplegic solution was 1000 to $2000 \mathrm{ml}$.

The right lateral incision (right lateral group) was made between the confluence of the right pulmonary veins and the interatrial groove. The right lateral incision was 
Table I. Patient factors

\begin{tabular}{|c|c|c|c|c|c|c|}
\hline & Right lateral & $\begin{array}{l}p \text { Value } \\
(R L \text { vs } S S)\end{array}$ & Superior septal & $\begin{array}{l}p \text { Value } \\
\text { (SS vs TS) }\end{array}$ & Transseptal & $\begin{array}{l}p \text { Value } \\
(T S \text { vs } R L)\end{array}$ \\
\hline Age (yr) & 57.47 (SD14.47) & NS & 57.67 (SD13.47) & NS & 56.05 (SD14.13) & NS \\
\hline Female sex & $34 / 66(52 \%)$ & NS & $30 / 46(65 \%)$ & NS & $20 / 37(54 \%)$ & NS \\
\hline Emergency operation & $6 / 66(9 \%)$ & NS & $1 / 46(2 \%)$ & NS & $0 / 37(0 \%)$ & NS \\
\hline Recent myocardial infarction & $7 / 65(11 \%)$ & NS & $5 / 46(11 \%)$ & NS & $4 / 37(11 \%)$ & NS \\
\hline Smoking history & $17 / 66(26 \%)$ & NS & $8 / 46(17 \%)$ & NS & $11 / 37(30 \%)$ & NS \\
\hline Hypertension history & $22 / 66(33 \%)$ & NS & $18 / 46(39 \%)$ & NS & $15 / 37(41 \%)$ & NS \\
\hline Diabetes & $5 / 61(8 \%)$ & NS & $7 / 46(15 \%)$ & NS & $6 / 37(16 \%)$ & NS \\
\hline NYHA class & 3.48 (SD0.685) & 0.005 & $3.78(\mathrm{SD} 0.417)$ & NS & $3.57(\mathrm{SD} 0.685)$ & NS \\
\hline Ejection fraction & 46.82 (SD11.85) & NS & 49.11 (SD10.57) & NS & 46.08 (SD12.59) & NS \\
\hline Body surface area & $1.80(\mathrm{SD} 0.241)$ & NS & 1.78 (SD0.185) & NS & 1.85 (SD0.483) & NS \\
\hline Left ventricular end-diastolic pressure & $14.65(\mathrm{SD} 8.64)$ & NS & $14.58(\mathrm{SD} 7.44)$ & 0.003 & $20.06(\mathrm{SD} 8.25)$ & NS \\
\hline Pulmonary artery systolic pressure & $53.72($ SD20.32) & NS & $57.56(\mathrm{SD} 22.61)$ & NS & $59.29(\mathrm{SD} 21.36)$ & NS \\
\hline Pulmonary artery diastolic pressure & 24.89 (SD11.82) & NS & $24.82(\mathrm{SD} 11.88)$ & NS & $27.59(\mathrm{SD} 8.57)$ & NS \\
\hline Diseased aortic valve & $14 / 66(21 \%)$ & NS & $14 / 46(30 \%)$ & NS & $8 / 37(22 \%)$ & NS \\
\hline Diseased tricuspid valve & $2 / 66(3 \%)$ & 0.001 & $11 / 46(24 \%)$ & 0.034 & $17 / 37(46 \%)$ & 0.000 \\
\hline Mitral valve stenosis & $18 / 66(27 \%)$ & NS & $12 / 46(26 \%)$ & NS & $6 / 37(16 \%)$ & NS \\
\hline Mitral valve insufficiency & $40 / 66(61 \%)$ & NS & $24 / 46(52 \%)$ & NS & $25 / 37(68 \%)$ & NS \\
\hline $\begin{array}{l}\text { Mitral valve with both stenosis and } \\
\text { insufficiency }\end{array}$ & $7 / 66(11 \%)$ & NS & $9 / 46(20 \%)$ & NS & $6 / 37(16 \%)$ & NS \\
\hline Rheumatic mitral valve & $34 / 66(52 \%)$ & NS & $23 / 46(50 \%)$ & NS & $17 / 37(46 \%)$ & NS \\
\hline Barlow floppy mitral valve & $16 / 66(24 \%)$ & NS & $10 / 46(22 \%)$ & NS & $9 / 37(24 \%)$ & NS \\
\hline Ischemic mitral valve & $9 / 66(14 \%)$ & NS & $6 / 46(13 \%)$ & NS & $3 / 37(8 \%)$ & NS \\
\hline $\begin{array}{l}\text { Mitral valve with other pathologic } \\
\text { condition }\end{array}$ & $7 / 66(11 \%)$ & NS & $7 / 46(15 \%)$ & NS & $8 / 37(22 \%)$ & NS \\
\hline Reoperation & $6 / 66(9 \%)$ & 0.016 & $12 / 46(26 \%)$ & NS & $15 / 37(41 \%)$ & 0.000 \\
\hline \multicolumn{7}{|l|}{ Preop. atrial rhythm } \\
\hline Sinus rhythm & $44 / 66(67 \%)$ & NS & $28 / 46(61 \%)$ & 0.020 & $11 / 37(35 \%)$ & 0.002 \\
\hline Atrial fibrillation & $21 / 66(32 \%)$ & NS & $17 / 46(37 \%)$ & NS & $20 / 37(54 \%)$ & 0.027 \\
\hline Paced & $1 / 66(2 \%)$ & NS & $1 / 46(2 \%)$ & NS & $3 / 37(8 \%)$ & NS \\
\hline Unknown & & NS & & NS & $1 / 37(3 \%)$ & NS \\
\hline
\end{tabular}

$R L$, Right lateral; SS, superior septal; TS, transseptal; SD, standard deviation; NS, not significant ( $p>0.05$ ); NYHA, New York Heart Association.

Table II. Operative factors

\begin{tabular}{|c|c|c|c|c|c|c|}
\hline & Right lateral & $\begin{array}{c}p \text { Value } \\
(R L \text { vs } S S)\end{array}$ & Superior septal & $\begin{array}{c}p \text { Value } \\
(S S \text { vs } T S)\end{array}$ & Transseptal & $\begin{array}{c}p \text { Value } \\
(T S \text { vs } R L)\end{array}$ \\
\hline Associated CABG & $24 / 66(36 \%)$ & NS & $10 / 46(22 \%)$ & NS & $12 / 37(32 \%)$ & NS \\
\hline Associated aortic valve procedure & $11 / 66(17 \%)$ & NS & $5 / 46(11 \%)$ & NS & $5 / 37(14 \%)$ & NS \\
\hline Associated tricuspid procedure & $1 / 66(2 \%)$ & 0.000 & $10 / 46(22 \%)$ & 0.000 & $22 / 37(60 \%)$ & 0.000 \\
\hline Perfusion time (min) & $125.20(\mathrm{SD} 52.28)$ & NS & $110.22(\mathrm{SD} 37.66)$ & 0.002 & $137.65(\mathrm{SD} 39.89)$ & NS \\
\hline Crossclamp time (min) & $73.73(\mathrm{SD} 31.13)$ & NS & $71.11(\mathrm{SD} 26.96)$ & NS & $76.54(\mathrm{SD} 26.22)$ & NS \\
\hline Mitral valve replacement & $48 / 66(73 \%)$ & 0.006 & $43 / 46(93 \%)$ & NS & $32 / 37(87 \%)$ & NS \\
\hline Mitral valve repair & $18 / 46(27 \%)$ & 0.006 & $3 / 46(7 \%)$ & NS & $5 / 37(14 \%)$ & NS \\
\hline
\end{tabular}

RL, Right lateral; $S S$, superior septal; $T S$, transseptal; $N S$, not significant $(p>0.05)$.

usually extended inferiorly between the right inferior pulmonary vein and the inferior vena cava. ${ }^{8}$ The atriotomy closure was $50 \%$ to $90 \%$ complete before the aortic clamp was removed.

The superior septal incision (superior septal group) was begun anteriorly in the trabeculated portion of the right atrium 1 to $2 \mathrm{~cm}$ from the atrioventricular groove. The right atrial incision was extended superiorly into the atrial appendage. The atrial septum was visualized and a vertical incision made in the fossa ovalis of the atrial septum. With visualization of the right and left atrial cavities and the dome of the left atrium behind the aorta, the two incisions were connected superiorly and extended onto the superior portion of the left atrium behind the aorta. Care was taken to keep the incision far enough from the aortic anulus to permit easy and secure closure. Several recent publications show this incision in drawings and photographs. ${ }^{1,3,5-7}$ The atrial septum, superior wall of the left 
Table III. Postoperative factors

\begin{tabular}{|c|c|c|c|c|c|c|}
\hline & Right lateral & $\begin{array}{c}p \text { Value } \\
(R L \text { vs } S S)\end{array}$ & Superior septal & $\begin{array}{c}p \text { Value } \\
(S S \text { ws TS })\end{array}$ & Transseptal & $\begin{array}{c}p \text { Value } \\
(T S \text { vs } R L)\end{array}$ \\
\hline Mortality & $4 / 66(6 \%)$ & NS & $2 / 45(4 \%)$ & NS & $3 / 37(8 \%)$ & NS \\
\hline Postoperative bleeding & $4 / 66(6 \%)$ & NS & $3 / 46(7 \%)$ & NS & $5 / 37(14 \%)$ & NS \\
\hline Perioperative myocardial infarction & $1 / 66(2 \%)$ & NS & $1 / 46(2 \%)$ & NS & $0 / 37$ & NS \\
\hline Postoperative renal failure & $5 / 66(8 \%)$ & NS & $2 / 46(4 \%)$ & NS & $4 / 37(11 \%)$ & NS \\
\hline Postoperative pulmonary failure & $11 / 66(17 \%)$ & 0.015 & $1 / 46(2 \%)$ & 0.047 & $5 / 37(14 \%)$ & NS \\
\hline Intraaortic balloon pump & $8 / 66(12 \%)$ & NS & $4 / 46(9 \%)$ & NS & $6 / 37(16 \%)$ & NS \\
\hline Postoperative stroke & $3 / 65(5 \%)$ & NS & $1 / 42(2 \%)$ & NS & $0 / 37$ & NS \\
\hline Postoperative infection & $13 / 66(20 \%)$ & NS & $5 / 46(11 \%)$ & NS & $8 / 37(22 \%)$ & NS \\
\hline Postoperative permanent pacemaker & $6 / 65(9 \%)$ & 0.020 & $8 / 45(18 \%)$ & NS & $6 / 33(18 \%)$ & NS \\
\hline Sternal complications & $1 / 65(2 \%)$ & NS & $1 / 42(2 \%)$ & NS & $1 / 37(3 \%)$ & NS \\
\hline \multicolumn{7}{|l|}{ Postoperative rhythm } \\
\hline Sinus rhythm & $39 / 66(59 \%)$ & 0.003 & $14 / 46(30 \%)$ & NS & $10 / 37(27 \%)$ & 0.002 \\
\hline Atrial fibrillation & $18 / 66(27 \%)$ & NS & $20 / 46(43 \%)$ & NS & $14 / 37(38 \%)$ & NS \\
\hline Nodal rhythm & $1 / 66(2 \%)$ & NS & $2 / 46(4 \%)$ & NS & $3 / 37(8 \%)$ & NS \\
\hline Paced & $7 / 66(11 \%)$ & NS & $9 / 46(20 \%)$ & NS & $9 / 37(24 \%)$ & NS \\
\hline Unknown & $1 / 66(2 \%)$ & NS & $1 / 46(2 \%)$ & NS & $1 / 37(3 \%)$ & NS \\
\hline
\end{tabular}

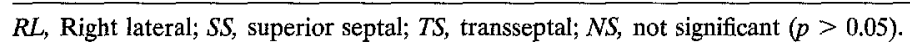

atrium, and the superior right atrial wall were closed with the aorta clamped after the left atrium, left ventricle, and aorta were filled with blood.

The transseptal incision (transseptal group) was begun much the same as the superior septal incision. The right atrial incision was extended into the appendage and the septal incision was begun in the fossa ovalis and extended superiorly into the adjacent portion of the muscular atrial septum. McGrath, Levett, and Gonzalez-Levin ${ }^{9}$ and Bowman and Malm $^{10}$ have published illustrations of this incision. The atrial septum was closed with the aorta clamped after the left side of the heart was filled with saline solution and blood.

Self-retaining retractors were used for exposing the mitral valve. When the superior septal incision was used retractors were often not necessary and retraction sutures were usually sufficient to expose the mitral valve. All atrial incisions were closed with running 3-0 polypropylene suture.

Analysis of differences of individual factors among groups was done by single regression or $\chi^{2}$ analysis. Determination of factors that contributed to the prediction of postoperative outcomes was by multiple regression analysis. We showed trends in the associated conditions in patients having mitral valve operations over a period of 9 years by showing changing proportions of patients with recent myocardial infarction or requiring coronary artery bypass grafting (CABG). This analysis included 157 patients.

\section{Results}

Analysis of patient factors showed the following significant $(p<0.05)$ differences (Table I). Mean New York Heart Association functional class was greater in the superior septal group compared with that in the right lateral group. Mean left ventricular end-diastolic pressure was greater in the transseptal group compared with that in the superior septal group. Associated tricuspid valve disease was more common in the transseptal group than in either the right lateral or superior septal groups. Reoperation was more common in the superior septal and transseptal groups than in the right lateral group. Preoperative sinus rhythm was more common in the superior septal and right lateral groups than in the transseptal group. Preoperative atrial fibrillation was more common in the transseptal group.

Significant $(p<0.05)$ differences were observed among the groups in several operative factors (Table II). Tricuspid valve procedures were more common in the transseptal group than in the superior septal and right lateral groups. Perfusion time was greater in the transseptal and right lateral groups than in the superior septal group. Mitral valve reconstruction was done more commonly in the right lateral group than in the superior septal or transseptal groups.

Differences in postoperative factors among the groups reached significance $(p<0.05)$ in only a few instances (Table III). Pulmonary failure was less common in the superior septal group than in the transseptal or right lateral groups. Permanent pacemaker was necessary more often in the superior septal group than in the right lateral group. Sinus rhythm was more common after operation in the right lateral group than in the transseptal or superior septal groups.

Patients were then grouped according to preoperative rhythm. Table IV shows the discharge 
Table IV. Discharge rhythm

\begin{tabular}{|c|c|c|c|c|c|c|}
\hline & Right lateral & $\begin{array}{c}p \text { Value } \\
(R L \text { vs } S S)\end{array}$ & Superior septal & $\begin{array}{c}p \text { Value } \\
\text { (SS vs TS) }\end{array}$ & Transseptal & $\begin{array}{c}p \text { Value } \\
(T S \text { vs } R L)\end{array}$ \\
\hline \multicolumn{7}{|c|}{ Preoperative sinus rhythm } \\
\hline \multicolumn{7}{|c|}{ Postoperative rhythm } \\
\hline Sinus rhythm & $35 / 44(80 \%)$ & 0.004 & $13 / 28(46 \%)$ & NS & $9 / 13(69 \%)$ & NS \\
\hline Atrial fibrillation & $6 / 44(14 \%)$ & NS & $6 / 28(21 \%)$ & NS & $0 / 13$ & NS \\
\hline Nodal rhythm & $1 / 44(2 \%)$ & NS & $2 / 28(7 \%)$ & NS & $2 / 13(15 \%)$ & NS \\
\hline Paced & $1 / 44(2 \%)$ & 0.007 & $6 / 28(21 \%)$ & NS & $2 / 13(15 \%)$ & NS \\
\hline \multicolumn{7}{|c|}{ Preoperative atrial fibrillation } \\
\hline \multicolumn{7}{|c|}{ Postoperative rhythm } \\
\hline Sinus rhythm & $4 / 21(19 \%)$ & NS & $1 / 17(6 \%)$ & NS & $1 / 20(5 \%)$ & NS \\
\hline Atrial fibrillation & $12 / 21(57 \%)$ & NS & $14 / 17(82 \%)$ & NS & $14 / 20(70 \%)$ & NS \\
\hline Nodal rhythm & $0 / 21$ & NS & $0 / 17$ & NS & $1 / 20(5 \%)$ & NS \\
\hline Paced & $5 / 21(24 \%)$ & NS & $2 / 17(12 \%)$ & NS & $4 / 20(20 \%)$ & NS \\
\hline
\end{tabular}

$R L$, Right lateral; $S S$, superior septal; $T S$, transseptal; $N S$, not significant $(p>0.05)$.

rhythm in patients whose preoperative rhythm was sinus rhythm or atrial fibrillation. In patients with preoperative sinus rhythm, postoperative sinus rhythm was significantly $(p<0.05)$ more common in the right lateral group than in the superior septal group. Permanent pacemaker was significantly $(p<$ $0.05)$ more common in the superior septal group than in the right lateral group. No significant differences in discharge rhythm were observed in patients whose preoperative rhythm was atrial fibrillation.

Because significant differences among the three groups were observed in patient, operative, and postoperative factors, multivariate analysis was used to determine which patient factors, operative factors, and type of atrial incision were predictors of postoperative outcomes. Table $\mathrm{V}$ shows the result of this analysis. None of the patient and operative factors that were different among the groups were predictors of adverse postoperative outcomes. Right lateral and transseptal groups were predictive of preservation of sinus rhythm after operation.

The trends in percent of patients with mitral valve disease who require CABG or who have recent myocardial infarction are shown in Figs. 1 and 2. These figures show that the percent of patients with coronary artery disease or recent myocardial infarction is increasing.

\section{Discussion}

The technical advantages of the superior septal incision have been appreciated by many surgeons in recent years partly because of the changing spectrum of patients having mitral valve procedures. The proportion of patients having mitral valve procedures who require reoperation or mitral valve repair is increasing. ${ }^{5,7,8}$ During a 9-year period we ob-
Table V. Determinants of adverse outcomes (multiple regression analyses)

\begin{tabular}{lcc}
\hline & $R^{2}$ & $\operatorname{Sig} T$ \\
\hline Postop. pulmonary failure & & \\
$\quad$ Associated CABG & 0.1015 & 0.0003 \\
$\quad$ Emergency operation & 0.1417 & 0.0106 \\
Postop. permanent pacemaker & & \\
$\quad$ Mitral insufficiency & 0.0386 & 0.0290 \\
$\quad$ Age & 0.0689 & 0.0324 \\
Preop. and postop. sinus rhythm & & \\
$\quad$ Right lateral or transseptal incision & 0.4977 & 0.0071 \\
$\quad$ Time since myocardial infarction & 0.5139 & 0.0309 \\
\hline
\end{tabular}

served an increasing incidence of coronary artery disease and recent myocardial infarction among patients having mitral valve operation. There has also been increasing emphasis on mitral valve repair. We agree that mitral valve repair is easier through the superior septal incision. ${ }^{1-7}$

Mortality for mitral valve procedures was not significantly different among the three atrial incision groups. The lower prevalence of pulmonary failure in the superior septal group may be a reflection of the "fast tracking" of patients recently. We first used the superior septal incision in 1987 but have used it with increasing frequency.

This study confirms that there is jeopardy in the failure to preserve sinus rhythm in the early postoperative period in the superior septal group. ${ }^{4} \mathrm{We}$ observed the return of sinus rhythm during the postoperative period in many patients in the superior septal group. Our indication for permanent pacemaker was either complete heart block or persistent bradycardia after operation. Patients with persistent bradycardia who are otherwise ready for discharge from the hospital present a challenging 


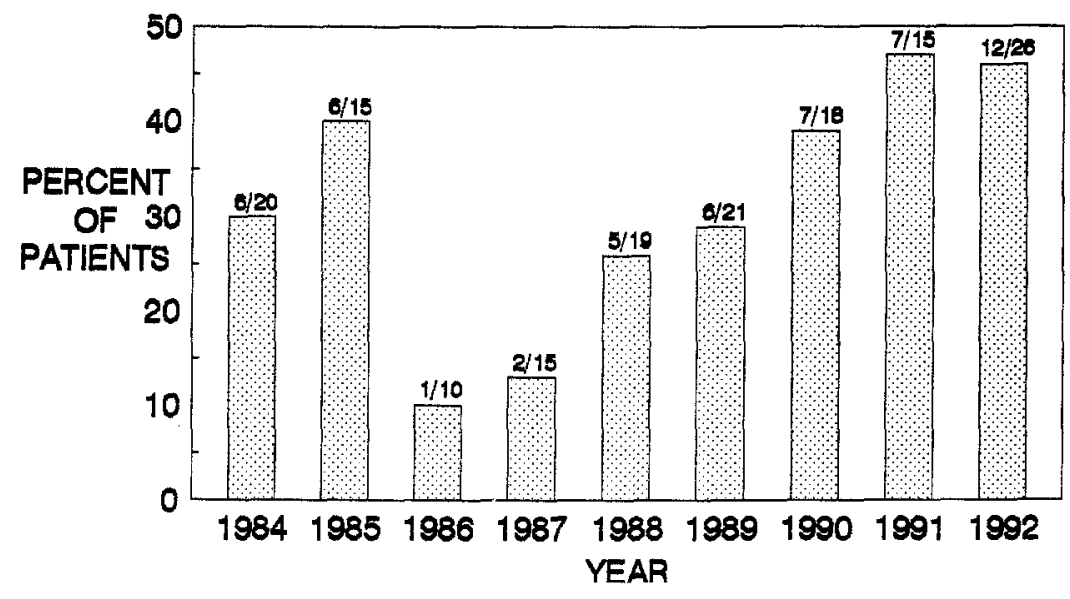

Fig. 1. $C A B G$ and mitral valve operation.

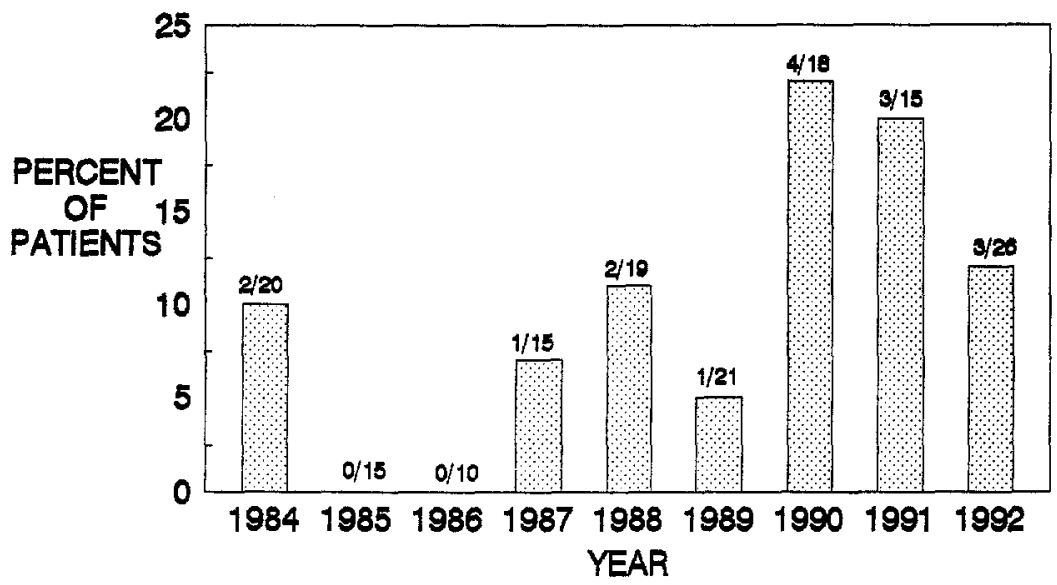

Fig. 2. Recent myocardial infarction and mitral valve operation.

decision. One must determine whether to continue hospitalization with temporary pacing or to place a permanent pacemaker. The placement of permanent pacemakers for complete heart block or bradycardia with underlying sinus rhythm, nodal rhythm, or atrial fibrillation was observed in all three groups. There was no significant difference between the groups in occurrence of need for permanent pacing or the underlying rhythm necessitating permanent pacing.

Aortic crossclamp times were similar in all groups. Perfusion time was longer in the transseptal group compared with times in the other two groups. Tricuspid valve procedures were more common in the transseptal group and were commonly done after the aortic clamp was removed. This probably accounts for the significantly longer perfusion time in the transseptal group. It is our impression that atrial closure takes more time with the aorta clamped with the superior septal incision, but this is more than compensated for by the time saved because the valve operation is easier and faster with the superior septal incision.

We have found the superior septal incision to be a significant advantage in patients with a small left atrium and in patients who require reoperation. The superior septal approach would appear to be the incision of choice in patients in chronic atrial fibrillation. For patients in sinus rhythm before operation, failure to return to sinus rhythm in the short term was $54 \%$ for the superior septal incision, $20 \%$ for the right lateral incision, and $31 \%$ for the transseptal incision. There is risk of loss of sinus rhythm with either of the three atrial incisions, but the risk is greatest with the superior septal incision. For patients in sinus rhythm one must weigh the 
advantages of the superior septal incision versus the risk of the loss of sinus rhythm.

We agree with Barner ${ }^{2}$ that the superior septal approach provides the best exposure of the mitral valve. It is the preferred approach for all reoperations. In primary operations we use it in all patients not in sinus rhythm and in patients with sinus rhythm when the atrium is small, when the chest is deep, or when difficult exposure is anticipated for other reasons. With the superior septal approach the mitral valve may be exposed with minimal retraction of the sternum, which, in our opinion, reduces the risk of brachial plexus pain and dysfunction and the risk of sternal infection and nonunion.

\section{REFERENCES}

1. Alfieri O, Sandrelli L, Pardini A, et al. Optimal exposure of the mitral valve through an extended vertical transseptal approach. Eur J Cardiothorac Surg 1991;5:294-9.

2. Barner HB. 1992 update (1985: combined superior and right lateral left atriotomy with division of the superior vena cava for exposure of the mitral valve). Ann Thorac Surg 1992;54:594.

3. Smith CR. Septal-superior exposure of the mitral valve. J Thorac Cardiovasc Surg 1992;103:623-8.

4. Smith CR. Efficacy and safety of the superior-septal approach to the mitral valve [Editorial]. Ann Thorac Surg 1993;55:1357-8.

5. Kon ND, Tucker WY, Mills SA, Lavender SW, Cordell AR. Mitral valve operation via an extended transseptal approach. Ann Thorac Surg 1993;55:1413-7.

6. Guiraudon GM, Ofiesh JG, Kaushik R. Extended vertical transatrial septal approach to the mitral valve. Ann Thorac Surg 1991;52:1058-62.

7. Berreklouw E, Ercan H, Schonberger JP. Combined superior-transseptal approach to the left atrium. Ann Thorac Surg 1991;51:293-5.

8. Agathos EA, Starr A. Mitral valve replacement. Curr Probl Surg 1993; June:485-592.

9. McGrath LB, Levett JM, Gonzalez-Levin L. Safety of the right atrial approach for combined mitral and tricuspid valve procedures. J Thorac Cardiovasc SURG 1988;96:756-9.

10. Bowman FO, Malm JR. The transseptal approach to mitral valve repair. Arch Surg 1965;90:329-31.

11. Utley JR, Wallace DJ, Thomason ME, et al. Correlates of preoperative hematocrit value in patients undergoing coronary artery bypass. J THORAC CARDIOVASC SURG 1989;98:451-3.

12. Pinkard J, Utley JR, Leyland SA, Morgan M, Johnson $\mathrm{H}$. Relative risk of aortic and femoral insertion of intraaortic balloon pump after coronary artery bypass grafting procedures. J Thorac CARdiovasc SuRG 1993;105:721-8.

13. Utley JR, Leyland SA, Johnson HD, et al. Correlation of preoperative factors, severity of disease, type of oxygenator and perfusion times with mortality and morbidity of coronary bypass. Perfusion 1991;6:15-22.

14. Utley JR, Morgan MS, Johnson HD, Wilde CM, Bell MS. Correlates of blood volume, red cell mass and plasma volume in coronary bypass patients. Perfusion 1989;4:205-11.

15. Utley JR, Thomason ME, Wallace DJ, et al. Preoperative correlates of impaired wound healing after saphenous vein excision. I THORAC CARDIOVASC SURG 1989;98:147-9. 